\title{
Membrane potential, serum calcium and serum selenium decrease in preeclampsia subjects in Owerri
}

\author{
Johnkennedy Nnodim*, Nwodo Emmanuel**, Okorie Hope*, Constance Nwadike*, \\ Edward Ukamaka*, and Onah Christian***
}

ABSTRACT

\section{BACKGROUND}

Pre-eclampsia is a serious hypertensive condition of pregnancy associated with high maternal and fetal morbidity and mortality. Women who have had pre-eclampsia have a greater risk of developing hypertension, stroke and ischemic heart disease in later life. The etiology of pre-eclampsia remains unclear. Placental insufficiency plays a key role in the progression of this disease. The aim of this study was to determine membrane potential, serum calcium and serum selenium levels in preeclampsia subjects in Owerri.

\section{METHODS}

A case control study involving 200 primigravida (100 preeclamptic and 100 apparently healthy) between the ages of 20 and 32 years attending General Hospital Owerri. Fasting venous blood was collected for the determination of serum selenium and serum calcium while membrane potential was calculated using the Nernst equation. The serum calcium was estimated using Randox Kit and serum selenium by atomic absorption spectrophotometry. The Independent Student $t$ test was used for statistical analysis.

\section{RESULTS}

The results revealed that membrane potential and serum selenium as well as serum calcium were significantly decreased in preeclampsia when compared with the controls, at $\mathrm{p}<0.05$.

\section{CONCLUSION}

Our study demonstrated that the decrease in membrane potential, serum calcium and serum selenium levels may play a critical role in the pathogenesis of pre-eclampsia. There may be a need for increasing the dietary intake of these essential trace metals during pregnancy to prevent pre-eclampsia in Owerri.

Keywords: Membrane potential, selenium, calcium, preeclampsia
*Department of Medical Laboratory Science, Faculty of Health Science, Imo State University Owerri, Imo State, Nigeria **Department of Biochemistry, Odimegwu Ojukwu University Uli, Anambra State, Nigeria ***Department of Chemical Pathology, Nnamdi Azikiwe University Teaching Hospital, Nnewi, Anambra State, Nigeria

\section{Correspondence :}

Johnkennedy Nnodim

Department of Medical Laboratory Science, Faculty of Health Science, Imo State University Owerri, Imo State, Nigeria Email: johnkennedy23@yahoo.com Phone: +238034237000

Date of first submission, April 20, 2017 Date of final revised submission, June 6, 2017

Date of acceptance, June 7, 2017

This open access article is distributed under a Creative Commons Attribution-Non Commercial-Share Alike 4.0 International License

Cite this article as: Nnodim J, Emmanuel $\mathrm{N}$, Hope O, Nwadike C, Ukamaka E, Christian O. CMembrane potential, serum calcium and serum selenium decrease in preeclampsia subjects in Owerri. Univ Med 2017;36:88-93. doi: 10.18051/UnivMed.2017.v36.88-93 


\section{INTRODUCTION}

Preeclampsia is a major complication of pregnancy and remains an important cause of both maternal and fetal mortality and morbidity. ${ }^{(1)}$ Preeclampsia is a pregnancy-related disease and its physiopathology probably consists of multiple factors such as abnormal placentation, imbalance of angiogenesis regulators, and maternal immune maladaptation. It could begin early in pregnancy with a poor trophoblastic invasion of maternal spiral arteries, leading to subsequent placental ischaemia and insufficiency. ${ }^{(2)}$ The maternal response, which usually shows in the second half of pregnancy, is characterized by an increased systemic inflammatory response with high levels of proinflammatory cytokines. The resulting widespread endothelial dysfunction is responsible for the hypertension and proteinuria which are the main features of preeclampsia. Also, it has been reported that maternal hormonal disturbance arising from sleep deprivation or circadian rhythm disruption could retard fetal growth or result in complications of pregnancy. ${ }^{(3)}$ Preeclampsia mainly occurs during the second and third trimester of pregnancy and still remains a common condition in which hypertension occurs in pregnancy. Preeclampsia is characterized by having systolic blood pressure equal to or greater than $140 \mathrm{mmHg}$ and diastolic blood pressure equal to or greater than $90 \mathrm{mmHg}$ on at least two occasions six or more hours apart. Also, proteinuria results in preeclampsia. ${ }^{(4)}$

It has been reported that endothelial cell dysfunction and inflammation are considered to have a crucial role in the pathophysiologic mechanism of preeclampsia. Increased oxidative stress during preeclampsia results in increased generation of free radicals, lipid peroxides, reactive oxygen species and superoxide anion radicals to cause endothelial injury and disorders. Oxidative stress is an imbalance between the production of reactive oxygen and the biological system's ability to detoxify the reactive intermediates or easily repair the resulting damage. ${ }^{(5)}$ Every type of organism maintains a reducing environment within its cells, which is produced by enzymes that preserve the reduced state through a constant input of metabolic energy. Alterations in this normal redox state can cause toxic effects through the production of peroxides and free radicals that damage all components of the cell, including proteins, lipids and deoxyribonucleic acid (DNA). During preeclampsia, as a consequence of endothelial cell damage, increased amounts of reactive oxygen species are generated, including hydroxyl radicals, lipid peroxyl radicals, singlet oxygen and peroxynitrite formed from nitrogen oxide. ${ }^{(6)}$ All these chemical groups behave as a unit and constitute the free radicals. Hence preeclampsia involves generalized damage to the maternal endothelium with the release of vasoconstrictive factors. ${ }^{(7)}$

A growing body of evidence supports the understanding that preeclampsia begins in the utero-placental unit, is amplified by oxidative stress, and ends in the maternal endothelium. ${ }^{(8)}$ The precise mechanisms that lead to preeclampsia, which often occurs without warning and may follow a precipitous course, are not known.

Sodium levels are increased in preeclamptic patients compared to normal subjects. Hypernatraemia observed in this group could be caused by sodium retention. (9) As a result, hypokalaemia inhibits potassium channels in the cell membrane and depolarizes the membrane. Because of its electrogenic nature, the inhibition of the sodium pump itself decreases the membrane potential. ${ }^{(10)}$

Trace elements such as zinc ( $\mathrm{Zn}$ ), selenium $(\mathrm{Se})$ and copper $(\mathrm{Cu})$ display antioxidant activity, while others such as calcium $(\mathrm{Ca})$ and magnesium $(\mathrm{Mg})$ are essential micronutrients. ${ }^{(11)}$ The disturbance in the metabolism of these elements may be a contributing factor in the development of certain diseases such as preeclampsia observed in pregnant women. ${ }^{(12)}$ The essential trace mineral Se acting through selenoproteins/selenoenzymes has the capacity to reduce the risk of pre-eclampsia. ${ }^{(13)}$ 
Low serum calcium may cause high blood pressure by stimulating parathyroid hormone and renin release and also by inducing vasoconstriction by increasing its level in vascular smooth muscle. ${ }^{(14,15)}$ Calcium might also have an indirect effect on smooth muscle function by increasing magnesium levels. ${ }^{(16)}$ However, the role of calcium and selenium in pregnant women is still being discussed.

In recent times, there has been an increasing prevalence in the incidence of pre-eclampsia globally but there are conflicting reports on the relationship between trace elements and preeclampsia. Some studies have shown that changes in the levels of blood trace elements in pre-eclamptic patients may implicate its pathogenesis ${ }^{(17)}$ while others have failed to show an association of blood levels of trace elements and prevalence of pre-eclampsia. ${ }^{(18)}$

In this study, the level of membrane potential, serum calcium and serum selenium in women with preeclampsia were evaluated to provide information on their status in Owerri Imo State, Nigeria.

\section{METHODS}

\section{Research design}

This case control study was carried out from February 2014 to April 2015 at General Hospital Owerri.

\section{Research subjects}

The subjects of the study were 100 pregnant women within the age range of 20-32 years, who had been clinically diagnosed with preeclampsia during the third trimester (30-40 weeks), and were visiting General Hospital Owerri. Subjects were selected on the basis of high blood pressure (systolic and diastolic), proteinuria and pathological edema, which are the diagnostic criteria of preeclampsia. As normal controls were taken 100 healthy normotensive pregnant women, also within the age range of 20-32 years, who were in their third trimester (30-40 weeks). Patients with a past history of hypertension, diabetes, and renal disease were excluded from the study. The following information was recorded by the trial midwife: age, blood pressure; date of the last menstrual period/ gestational age; weight and height.

\section{Blood collection}

In all subjects $4 \mathrm{ml}$ of fasting venous blood was collected into plain and EDTA bottles. The serum was separated by centrifuging the whole blood in Westerfuge (model 684) centrifuge at $5,000 \mathrm{~g}$ for 10 minutes. After centrifugation, red blood cells were separated from the plasma, washed thrice with physiological saline and lysed with $1.0 \mathrm{ml}$ of distilled, deionized water. The red cell haemolysates were stored frozen until analysis.

\section{Biochemical assay}

The extracellular cation concentrations were estimated from serum samples while intracellular calcium concentrations were determined from lysed red blood cells. The serum calcium was estimated using Randox Kit CA590. While membrane potential was determined by calculation using the Nernst equation. Selenium was determined by atomic absorption spectrophotometry.

\section{Statistical analysis}

The values were expressed as mean \pm standard deviation. The independent Student ttest was used to calculate the significant differences at $\mathrm{p}<0.05$.

\section{Ethical clearance}

Consent as well as ethical approval was obtained from the ethical committee of the General Hospital Owerri (GHO/14/011).

\section{RESULTS}

The present study enrolled 200 pregnant women, among whom the mean age of women with pre-eclampsia was lower than that of controls $(22.51 \pm 3.42$ yrs vs $23.55 \pm 3.11$ yrs $)$ 
Table 1. Clinical characteristics of pre-eclampsia subjects and controls

\begin{tabular}{lccc}
\hline \multicolumn{1}{c}{ Clinical characteristic } & $\begin{array}{c}\text { Pre-eclampsia } \\
(\mathbf{n}=\mathbf{1 0 0})\end{array}$ & $\begin{array}{c}\text { Controls } \\
(\mathbf{n}=\mathbf{1 0 0})\end{array}$ & p value \\
\hline Age (years) & $22.51 \pm 3.42$ & $23.55 \pm 3.11$ & $\mathrm{p}>0.05$ \\
BMI (kg/m $\left.{ }^{2}\right)$ & $24.99 \pm 2.11$ & $23.84 \pm 2.41$ & $\mathrm{p}>0.05$ \\
Gestational age (weeks) & $35.26 \pm 3.29$ & $38.84 \pm 4.01$ & $\mathrm{p}<0.05$ \\
Systolic BP (mmHg) & $142.29 \pm 6.81$ & $115.10 \pm 5.11$ & $\mathrm{p}<0.05$ \\
Diastolic BP (mmHg) & $94.02 \pm 8.33$ & $76.63 \pm 6.00$ & $\mathrm{p}<0.05$ \\
\hline
\end{tabular}

but the difference was statistically not significant $(\mathrm{p}>0.05)$. Mean body mass index (BMI) was higher in pre-eclampsia subjects than in controls $\left(24.99 \pm 2.11 \mathrm{~kg} / \mathrm{m}^{2}\right.$ vs $23.84 \pm 2.41 \mathrm{~kg} / \mathrm{m}^{2}$, but again the difference was statistically not significant $(\mathrm{p}>0.05)$. The gestational age was significantly lower in pre-eclampsia subjects $(p<0.05)$ (Table 1). Systolic and diastolic blood pressures were significantly higher in the preeclampsia subjects $(\mathrm{p}<0.05)$.

The levels of membrane potential, serum selenium and calcium and red cell calcium were decreased in preeclampsia when compared with the controls $(\mathrm{p}<0.05)$ (Table 2).

\section{DISCUSSION}

In our study, BMI was higher in the preeclampsia group compared to the control group, but the difference was not significant. This result differs from the study of Akhtar et al. ${ }^{(19)}$ and Kanagal et al. ${ }^{(20)}$ who found a significantly higher BMI in the preeclampsia group. Women with high BMI tend to have hypertension, as compared with women with low BMI. ${ }^{(20)}$

Preeclampsia is linked with increased utilization of antioxidants. Antioxidants neutralize toxins and volatile free radicals that are referred to as atoms or groups of atoms possessing an unpaired electron. Among these are related reactive oxygen species (ROS) that lead to free radical generation, causing cascading chain reactions in biological systems. ${ }^{(3)}$

In this study, the membrane potential was significantly decreased in preeclampsia when compared with normal pregnancy. This is consistent with a study that found that plasma from pre-eclampsia women also had a significant decrease in mitochondrial membrane potential compared with normal pregnancy. ${ }^{(21)}$ This means that the energy in preeclampsia patients is very low, which is linked to their high blood pressure. In our study the serum calcium was significantly lower in the preeclampsia group, which is consistent with the work of Kanagal et al. ${ }^{(20)}$ Essentially similar results were obtained in a study in India, showing that plasma calcium levels were significantly lower in the preeclampsia group as compared with the control group. ${ }^{(22)}$ Similarly, in our study the intraerythrocytic calcium levels were shown to be significantly lower in preeclampsia as compared with controls. Consistent results were also obtained in the study by Igwe et al. ${ }^{(23)}$ In contrast, several studies showed that serum calcium levels in the group with preeclampsia were not significantly different from those in the group with normal pregnancy. ${ }^{(24,25)}$

Table 2. Membrane potential, calcium and selenium level in preeclampsia subjects and controls

\begin{tabular}{lccl}
\hline \multicolumn{1}{c}{ Parameter } & $\begin{array}{c}\text { Control } \\
(\mathbf{n = 1 0 0})\end{array}$ & $\begin{array}{c}\text { Pre-eclampsia } \\
(\mathbf{n = 1 0 0})\end{array}$ & p value \\
\hline Serum selenium $(\mu / \mathrm{L})$ & $69.18 \pm 2.44$ & $63.21 \pm 4.87$ & $\mathrm{p}<0.05$ \\
Red cell calcium $(\mathrm{mmol} / \mathrm{L})$ & $0.64 \pm 0.07$ & $0.56 \pm 0.15$ & $\mathrm{p}<0.05$ \\
Serum calcium $(\mathrm{mmol} / \mathrm{L})$ & $2.58 \pm 0.05$ & $1.73 \pm 0.13$ & $\mathrm{p}<0.05$ \\
Membrane potential $(\mathrm{J})$ & $241.88 \pm 42.85$ & $185.36 \pm 52.00$ & $\mathrm{p}<0.05$ \\
\hline
\end{tabular}


Furthermore, it was observed from our study that serum selenium level was significantly decreased in preeclampsia when compared with the control group. Selenium plays an important role as a cofactor for the reduction of antioxidant enzymes such as glutathione peroxidase, an enzyme reacting with potentially harmful oxidizing agents in substances like haemoglobin. High levels of glutathione function in the blood are linked with longevity. Deficiency of selenium may be associated with the severity of preeclampsia.

This is consistent with a case-control study in Bangladesh with 74 preeclampsia patients as cases and 118 normotensive pregnant women as controls from the same gestational period. This study showed that mean serum selenium concentration in preeclampsia patients was significantly lower than that of healthy pregnant women. ${ }^{(26)}$

The observed reductions in the calcium and selenium levels in pregnancy may be attributed, not only to preeclampsia, but also to increase in blood volume, and to poor mineral supplementation in pregnancy as well as their utilization for fetal growth. A limitation of our study was that we did not determine in detail the dietary history of our subjects, so that we did not know the intakes of calcium and selenium in our study subjects. Further studies should be done to investigate the relationship between intakes of calcium, selenium, and other electrolytes in preeclampsia and the importance of calcium and selenium supplementation for the prevention of preeclampsia

\section{CONCLUSIONS}

This study showed a significant reduction of membrane potential, serum calcium and selenium level in preeclampsia compared to normal pregnancy. This demonstrates the importance of monitoring the serum calcium and serum selenium concentrations during antenatal examinations for reducing the incidence of preeclampsia.

\section{CONFLICT OF INTEREST}

There is no conflict of interest.

\section{CONTRIBUTIONS}

JN contributed to the conception and writing of manuscript.NE contribute to data collection and critical revision of article. $\mathrm{OH}$ and OC contributed to data analysis and interpretation. $\mathrm{CN}$ and $\mathrm{EU}$ contributed to data collection. All authors read and approved the final manuscript.

\section{REFERENCES}

1. Nnodim JK, Ihim A, Uduji HI. Alterations in antioxidants enzymes and malondialdehyde status in preeclampsia. Asian Pacific J Trop Biomed 2012;S673-8.

2. Kashinakunti SV, Sunitha HK, Gurupadappa K, et al. Lipid peroxidation and antioxidant status in preeclampsia. Al Meen J Med Sci 2010;3:3841.

3. Mechiore K, Basky T. Maternal cardiac function in preeclampsia. Curr Opin Obstet Gynaecol 2011;23:440-7.

4. Ditisheim AJ, Dibner C, Philippe J, et al. Biological rhythms and preeclampsia. Front Endocrinol 2013;44:47. doi: 10.3389/fendo. 2013.00047.

5. Maynard SE, Karumanchi SA. Angiogenic factors and preeclampsia. Semin Nephrol 2013; 31:33-46.

6. Ayala DE, Hermida RC. Ambulatory blood pressure monitoring for the early identification of hypertension in pregnancy. Chronobiol Int 2013;30:233-59.

7. Pennington KA, Schlitt JM, Jackson DL, et al. Preeclampsia: multiple approaches for a multifactorial disease. Dis Model Mech 2012;5: 9-18.

8. Hansson SR, Nääv $\AA$, Erlandsson L. Oxidative stress in preeclampsia and the role of free fetal hemoglobin. Front Physiol 2015;5:516. doi: 10.3389/fphys. 2014.00516.

9. Tabassum H, Al-Jameil N, Ali MN, et al. Status of serum electrolytes in preeclamptic pregnant women of Riyadh, Saudi Arabia. Biomed Res 2015;26:219-24.

10. Iwamoto T. Vascular $\mathrm{Na}^{+} / \mathrm{Ca}^{2+}$ exchanger: implications for the pathogenesis and therapy 
of salt dependent hypertension. Am J Physiol Regul Integr Comp Physiol 2006;290:536-45.

11. Farzuin L, Sajadi F. Comparison of serum trace element levels in patients with or without preeclampsia. J Res Med Sci 2012;17:938-41.

12. Rathore S, Gupta A, Batra HS, et al. Comparative study of trace elements and serum ceruloplasmin level in normal and pre-eclamptic pregnancies with their cord blood. Biomed Res 2011;22:20710.

13. Rayman MP. Selenium and human health. Lancet 2012;379:1256-68.

14. Jain S, Sharma P, Kulshreshtha S, et al. The role of calcium, magnesium and zinc in preeclampsia. Biol Trace Elem Res 2010;133:16270.

15. Punthumapol C, Kittichotpanich B. Serum calcium, magnesium and uric acid in preeclampsia and normal pregnancy. J Med Assoc Thai 2008;91:968-72.

16. Hofmeyr GJ, Duley L, Atallah A. Dietary calcium supplementation for prevention of pre-eclampsia and related problems: a systematic review and commentary. BJOG 2007;114:933-43.

17. Bringman J, Gibbs C, Ahokas R. Differences in serum calcium and magnesium between gravidas with severe pre-eclampsia and normotensive controls. Am J Obstet Gynecol 2006;195:148. DOI- 10.1016/j.ajog.2006.10.519.

18. Caughey AB, Stotland NE, Washington AE, et al. Maternal ethnicity, paternal ethnicity and parental ethnic discordance: predictors of preeclampsia. Obstet Gynecol 2005;106:156-61.

19. Akhtar S, Begum S, Ferdousi S. Calcium and zinc deficiency in pre-eclamptic women. J Bangldesh Soc Physiol 2011;6:94-9.
20. Kanagal DV, Rajesh A, Rao K, et al. Levels of serum calcium and magnesium in preeclamptic and normal pregnancy: a study from Coastal India J Clin Diagn Res 2014;8:OC01-OC04.

21. Robinson NJ, Minchell LJ, Myers JE, et al. A potential role for free fatty acids in the pathogenesis of preeclampsia. J Hypertens 2009;27:1293-302.

22. Baruah K, Choudhury B, Borgohain MK, et al. A comparative study of the serum calcium level in normal pregnant and pre-eclamptic women attending Gauhati Medical College and Hospital. Int J Biomed Adv Res 2015;6:776-9. DOI: 10.7439/ijbar.

23. Igwe CU, Okafor PA, Ibegbulem CO, et al. Effect of pre-eclampsia on plasma and erythrocytic divalent cation concentrations and their bioenergetics of transport. Asian J Med Sci 2015;6:6:18-23. DOI: 10.3126/ajms.v612.1109.

24. Golmohammad LS, Amirabi A, Yazdian M, et al. Evaluation of serum calcium, magnesium, copper, and zinc levels in women with preeclampsia. Iran J Med Sci 2008;33:231-4.

25. Bera S, Siuli RA, Gupta S, et al. Study of serum electrolytes in pregnancy induced hypertension. J Indian Med Assoc 2011;109:546-8.

26. Haque M, Moghal R, Sarwar S, et al. Low serum selenium concentration is associated with preeclampsia in pregnant women from Bangladesh. J Trace Elem Med Biol 2016;33:215. https://doi.org/10.1016/j.jtemb.2015.08.002. 